University of Texas Rio Grande Valley

ScholarWorks @ UTRGV

Psychological Science Faculty Publications and

Presentations

College of Liberal Arts

8-14-2020

\title{
Unique and Cumulative Effects of Intimate Partner \\ Cybervictimization Types on Alcohol use in Lesbian, Gay, and Bisexual Emerging Adults
}

\author{
Oscar Trujillo \\ The University of Texas Rio Grande Valley \\ Jorge I. Cantu \\ The University of Texas Rio Grande Valley \\ Ruby Charak \\ The University of Texas Rio Grande Valley
}

Follow this and additional works at: https://scholarworks.utrgv.edu/psy_fac

Part of the Psychology Commons

\section{Recommended Citation}

Trujillo, O., Cantu, J. I., \& Charak, R. (2020). Unique and additive effects of intimate partner cybervictimization types on alcohol use in lesbian, gay, and bisexual emerging adults. Cyberpsychology, Behavior, and Social Networking. Advance online publication. doi.org/10.1089/cyber.2019.0773

This Article is brought to you for free and open access by the College of Liberal Arts at ScholarWorks @ UTRGV. It has been accepted for inclusion in Psychological Science Faculty Publications and Presentations by an authorized administrator of ScholarWorks @ UTRGV. For more information, please contact justin.white@utrgv.edu, william.flores01@utrgv.edu. 


\title{
Unique and Cumulative Effects of Intimate Partner Cybervictimization Types on Alcohol use in Lesbian, Gay, and Bisexual Emerging Adults
}

\author{
Oscar Trujillo, B.S. \\ Jorge I. Cantu, B.S. \\ Ruby Charak, Ph.D. \\ Department of Psychological Science, The University of Texas Rio Grande Valley, Edinburg,
} Texas.

Author for correspondence: Ruby Charak, Ph.D., Assistant Professor, Department of Psychological Science, The University of Texas Rio Grande Valley, 1201 W University Dr., Edinburg, Texas 78539. Ph: 956-665-3733.Email: charakruby@gmail.com

Please cite as (APA citation): Trujillo, O., Cantu, J. I., \& Charak, R. (2020). Unique and additive effects of intimate partner cybervictimization types on alcohol use in lesbian, gay, and bisexual emerging adults. Cyberpsychology, Behavior, and Social Networking. Advance online publication. doi.org/10.1089/cyber.2019.0773 


\begin{abstract}
The use of modern technology has inadvertently created newer platforms for intimate partner victimization to take place. The present study investigated (i) whether psychological, sexual, and stalking intimate partner cybervictimization (cyber IPV) types were uniquely associated with alcohol use, and (ii) whether there were additive effect of cyber IPV types on alcohol use, after controlling for histories of childhood maltreatment types, face-to-face intimate partner victimization among lesbian, gay, and bisexual (LGB) emerging adults. Participants were 277 self-identifying LGB individuals in the age range of $18-29$ years $(M=25.39, S D=2.77 ; 16.6 \%$ lesbian, $25.6 \%$ gay, $43 \%$ bisexual women). Participants completed an online questionnaire assessing cyber IPV types, namely, psychological, sexual, and stalking, five forms of childhood maltreatment, face-to-face IPV types (i.e., physical, psychological, and sexual) and alcohol use. Findings indicated that $29.2 \%(n=81)$ endorsed all three type of cyber IPV. Hierarchical regression analysis showed that only sexual cyber IPV was uniquely associated with alcohol use. In support of the cumulative risk hypothesis, those with exposure to three types of cyber IPV were more likely to have greater alcohol use compared to those with exposure to any one type of cyber IPV. Findings indicate that cyber IPV can lead to behavioral health challenges, such as an increase in alcohol use among LGB emerging adults. Findings call for interventions focusing on generating awareness regarding the ill-effects of cyber IPV, and for mental health professionals to develop treatment programs to aid in the wellbeing of the victim.
\end{abstract}

Keywords. cyber, intimate partner victimization, alcohol use, sexual minority, emerging adult, additive effect 


\section{Unique and Cumulative effects of Intimate Partner Cybervictimization Types on Alcohol use in Lesbian, Gay, and Bisexual Emerging Adults}

As the availability of modern-day technology increases, so does its significance in romantic relationships, especially among same-sex couples.1-3 Notably, the use of technology in romantic relationships also increases the avenues for intimate partner violence, henceforth referred to as cyber IPV.4-5 Prior studies in adolescents suggest that cyber IPV is a risk factor of alcohol use;6 however, few studies examine this association in lesbian, gay, and bisexual (LGB) emerging adults. Doing so would inform clinical interventions tailored toward alleviating the risk of alcohol use among IPV survivors.

Prior studies suggest that LGB individuals are at heightened risk for alcohol use.7-9 Moreover, research shows emerging adults use alcohol at higher rates.10 Individuals with diverse sexual identities are also known to have higher rates of psychological distress as explained in Meyer's minority stress theory.11 Because of higher exposure to distress, LGB individuals greatly benefit from research studying LGB populations specifically to understand and reduce minority health disparities. Furthermore, current research indicates LGB individuals are at heightened risk for multiple types of dating violence victimization, including cyber IPV.12-14

\section{Types of Cybervictimization and their Relation to Alcohol Use}

Cyber IPV is a multidimensional construct comprising three domains: psychological abuse, sexual abuse, and cyberstalking.15 Psychological cyber IPV considers harassing a partner through online means, intentionally mishandling information, or ignoring partner to hurt them. Second, sexual IPV refers to unwanted sharing of sexual information through technological means.15 Third, cyberstalking includes monitoring a partner's activity through social media, email account, GPS, etc., as well as taking and sending information to and from a partner's device 
without permission.

Watkins and colleagues found experiencing psychological cybervictimization and cyberstalking significant in determining alcohol use; however, sexual cybervictimization was not.15 Cyber IPV, like face-to-face IPV, has its own types and consequences that could be harmful, making it a unique and important area of research. When using these cyber IPV types, it is inferred that each type of cybervictimization influences alcohol use individually and that their combined additive properties have an accumulating and detrimental effect, similar to studies focusing on the additive effects of face-to-face IPV and childhood maltreatment types.16,17

Unique and additive models have been widely used to assess effects of exposure to multiple types of victimization within interpersonal relationships on a victim's health.18,19 Most studies on cyber IPV investigate a single form of abuse rather than the unique effects of cyber IPV types.20,21 Different cyber IPV types rarely transpire in isolation, therefore researchers must cautiously interpret studies investigating independent effects.22 Consequently, using a unique effect model may provide more accurate information on specific associations between these forms of abuse and related health concerns without the confounding effects. For this reason, our first goal in this study was to examine the unique effects of each cyber IPV type while controlling for face-to-face IPV and the different childhood maltreatment types.

Although the unique effects model provides valuable information, additive effect models address the impact multiple types of IPV have on an individual's wellbeing. The additive model aligns with the cumulative risk hypothesis, 23 which states that experiencing more victimization types results in greater adverse health concerns. Previous literature lacks studies examining the cumulative effect of multiple cyber IPV types. Drawing from studies on face-to-face IPV, 18,24 it is imperative to examine this effect in cyber IPV to identify whether an increasingly detrimental 
effect exists with each addition of a cyber IPV type on alcohol use. Given that cyber IPV predicts alcohol use among LGB emerging adults24,25 and that unique and additive models provide valuable insight on the effects of IPV types on health,14,24 the present study attempts to examine the unique and cumulative effects of psychological, sexual, and stalking cyber IPV, on alcohol use among LGB emerging adults.

\section{Controlling for Child Maltreatment, Face-to-Face IPV, Sexual Orientation, and Race/Ethnicity}

Childhood maltreatment and face-to-face IPV have been researched to a large extent, albeit among heterosexuals, and both are risk factors of alcohol use.27-30 Furthermore, LGB individuals are at heightened risk of exposure to childhood maltreatment and face-to-face IPV because of the minority stress risk factors (e.g., heterosexist experiences, microaggressions) that make LGB individuals particularly vulnerable in addition to the risk factors that affect heterosexuals.24,33,34 In line with the self-medication hypothesis, some survivors of interpersonal violence consume alcohol as a coping mechanism for overcoming emotional pain arising from a traumatic event.29,35-39 Because of this relation between childhood maltreatment and face-to-face IPV to alcohol use, it is important to control for these known risk factors in the current study.2730,33

Alcohol use prevalence rates show LGB individuals are at a heightened risk for alcohol dependence, especially lesbian women.40,41 Furthermore, emerging adults are also especially vulnerable to alcohol use.42 Additionally, people of color (i.e., Native Americans, Hispanics, and African Americans) are disproportionately impacted by alcohol consumption.43 These areas of concern illustrate the need for studies focusing on LGB emerging adults and their vulnerability to alcohol use. 


\section{The Present Study}

The aim of the present study was two-fold. First, to examine the unique effect of each cyber IPV type, namely, psychological, sexual, and stalking on alcohol use, after controlling for the effects of age, race/ethnicity, sexual orientation, child maltreatment types, and face-to-face IPV. Based on one prior study, it was hypothesized that psychological cyber IPV and cyberstalking would be uniquely associated with alcohol use.15 Second, to examine the cumulative effect of the three types of cyber IPV after controlling for the effects of age, race/ethnicity, sexual orientation, childhood maltreatment types, and face-to-face IPV. Based on the cumulative risk theory, 23 it was hypothesized that increasing exposure to cyber IPV types (i.e., exposure to two or three types of cyber IPV) would lead to an increase in alcohol use as suggested by prior research studies. 44

\section{Method}

\section{Participants}

The study sample consisted of 277 emerging adults 18-29 years old $(M=25.39, S D=$ 2.77) with 105 males, 171 females, and 1 who self-identified as intersex. Inclusion criteria were that participants be between the ages of 18-29 years, a United States citizen or legal resident, and have a current or former dating partner or spouse. The only exclusionary criterion was selfidentifying as any orientation other than LGB. At the time of the study, 240 participants were in an intimate relationship and 37 were not currently in an intimate relationship but had been in the past year.

\section{Procedure}

Participant recruitment occurred from July to August 2017 via Amazon's Mechanical Turk, a sourcing platform for gathering data from significantly more diverse samples than typical 
college samples from the United States. 45 Criteria for inclusion/exclusion was not mentioned in the consent form. After providing consent, participants were asked screener demographic questions regarding sexual orientation (heterosexual, lesbian, gay, bisexual, or other).

Participants who selected "heterosexual" or "other" were not administered the rest of the survey and were directed to the end of the survey, thanked for their time, and informed that they did not qualify for the study. Participants who qualified and completed the survey were paid $\$ 3.00$ for

participating. In the full survey, ten attention check items were included, of which $80 \%$ needed to be answered correctly for inclusion. The Institutional Review Board at the University of the corresponding author approved the study procedures.

\section{Measures}

Childhood maltreatment. The present study utilized the short version of the Childhood Trauma Questionnaire (CTQ-SF)46 to measure childhood maltreatment histories across five domains: emotional abuse, physical abuse, sexual abuse, emotional neglect, and physical neglect. CTQ-SF uses a 5-point Likert-type scale ( $0=$ never true; $5=$ very often true) for each question in each of the five facets of childhood maltreatment. In the present study, the Cronbach's alpha $(\alpha)$ for all subscales was acceptable $(\alpha \mathrm{s}=.72$ to .94$)$.

Face-to-face intimate partner victimization. To track face-to-face IPV, the short form of the Revised Conflict Tactics Scale was used on a referent time of one year. 47 This scale measures three tactics employed during conflict in an intimate relationship: negotiation, physical assault, and psychological aggression. Additionally, it measures two supplemental scales: injury from assault and sexual coercion. The present study uses the scales of physical assault, psychological aggression, and sexual coercion. With respect to LGB identity, two items were added to the psychological aggression items in face-to-face situations ('My partner threatened to 
out me...' and 'My partner asks or tells me to act straight around certain people').48 Frequency of victimization was rated on a 7-point Likert-scale ranging from 1=once in the past year to $8=$ this has never happened, with the option of indicating $7=$ not in the past year, but it did happen before. In the present study, the Cronbach's alpha $(\alpha)$ for all subscales was acceptable $(\alpha \mathrm{s}=.81$ to .95$)$.

Cybervictimization among intimate partners. The Cyberaggression in Relationships Scale (CARS) was used to assess three domains: psychological abuse, sexual abuse, and cyberstalking. 15 Studies examining the validity of the CARS suggest the psychological and stalking facets of cyber IPV are positively related to alcohol use.15 Frequency of victimization was rated on a 7-point Likert type scale ranging from $0=$ once in the past year to $7=$ this has never happened, with the option of $6=n o t$ in the past year, but it did happen. Specific to LGB identity, two items were added to psychological cyberaggression ('My partner threatened to out me...' and 'My partner asks or tells me to act straight around certain people').48. In the present study, the Cronbach's alpha $(\alpha)$ for all subscales was acceptable $(\alpha \mathrm{s}=.86$ to .90$)$.

Alcohol use. The Alcohol Use Disorders Identification Test (AUDIT) assesses drinking behavior and related challenges participants faced in the past six months.49 Behaviors related to alcohol were rated on a 5-point Likert type scale ( $0=$ never; $4=$ daily or almost daily) and summed. The AUDIT typically exhibits sensitivity higher than other self-report screening measures, and is consistent.50 In the present study, the Cronbach's alpha $(\alpha)$ was acceptable $(\alpha=.78)$. A cut-off score of 8 or higher on the AUDIT scale indicated harmful alcohol consumption. 49

\section{Statistical analysis}


First, demographic details were calculated to examine sample size and percentages. Second, bivariate correlation analyses were conducted to assess the association between all study variables. Third, two separate hierarchical regression analyses tested the unique and cumulative effect of cybervictimization on alcohol use. Participants' age, racial-ethnic status, and sexual orientation were simultaneously entered as covariates in Step 1. In Step 2, five forms of childhood maltreatment were entered as correlates of alcohol use. Next, three forms of face-toface victimization — psychological, physical, and sexual victimization—were entered as Step 3. Lastly, in Step 4 the individual forms of cyber aggression—sexual, stalking, and psychological cybervictimization — were entered to examine their unique effect on alcohol use. In the second hierarchical regression, Steps 1-3 were repeated; and Step 4 comprised exposure to any one type of cybervictimization as the reference group (coded as 0 ), and examined the effect of no cybervictimization, exposure to two forms of cybervictimization, and exposure to three forms of cybervictimization on alcohol use. This was done to examine the cumulative effects of the twoand three types of cyber IPV on alcohol use without considering the unique effects, which were accounted for in the first model.

\section{Results}

Table 1 depicts the frequency distribution of childhood maltreatment, face-to-face, and cyber IPV types across LGB men and women. Of the 46 participants who reported experiencing two types of cyber IPV, 4 experienced sexual and psychological cyber IPV, 4 experienced sexual cyber abuse and cyberstalking, and 28 experienced psychological cyber abuse and cyberstalking. Out of all the participants, only $20.7 \%(n=60)$ reported not having experienced any of the three face-to-face IPV types. Nearly $11 \%(n=30)$ had a score indicating harmful alcohol use on the AUDIT $(M=2.84, S D=3.96)$. Table 2 depicts the bivariate correlation between the study 
variables. Alcohol use was significantly and positively associated with age, racial-ethnic minority status, and all types of interpersonal victimization types (except for childhood neglect), including cyber IPV types.

\section{Unique Effect of Cybervictimization types on alcohol use (Hypothesis 1)}

The hierarchical model examining the unique effect of each cyber IPV type on alcohol use after controlling for demographic variables, types of childhood maltreatment, and face-toface IPV types, was significant. Among cyber aggression types, only sexual cyber IPV had a significant effect on alcohol use after controlling for covariates (Table 3). Furthermore, being a person of color (Step 1), facing childhood physical abuse, and physical neglect (Step 2), and being a survivor of face-to-face sexual assault (Step 3) significantly predicted alcohol use among LGB emerging adults.

\section{Cumulative Effect of Cyber IPV on Alcohol use (Hypothesis 2)}

The model examining the cumulative effect of cyber IPV types on alcohol use after controlling for demographic variables, types of childhood maltreatment, and face-to-face IPV, was significant (Table 4). The hierarchical regression indicated that exposure to three types of cyber IPV led to higher scores on alcohol use compared to only one type of cyber IPV. Additionally, no significant associations were found between those with exposure of two types, and no cyber IPV (versus one type of cyber IPV) and alcohol use (Table 4).

\section{Discussion}

Previous research shows certain cybervictimization types are associated with alcohol use; 15 however, no studies have tested these among LGB individuals after controlling for IPV types that are known risk factors of alcohol use. The present study aimed to test two hypotheses. The first built upon previous research on the self-medication hypothesis and cyber IPV 15,37 
theorizing that experiencing psychological cybervictimization and cyberstalking would be associated with alcohol use; however, the present study did not find support for this hypothesis as findings indicate only the unique role of sexual cyber IPV in predicting the use of alcohol. The second hypothesis was in accordance with the cumulative risk hypothesis in that LGB emerging adults exposed to three cybervictimization types reported higher alcohol use compared to experiencing none or less than three types.

The finding that only sexual cyber IPV is associated with increased alcohol use is in line with a previous study on college-students, although the study did not control for the same covariates.8 This stands in contrast to prior studies that indicate that cyberbullying was not associated with alcohol use in LGBT youth8; prior studies on sexual diverse young adults indicate that in-person sexual assault experiences predict alcohol use and heavy episodic drinking.51,52 Furthermore, the associations between psychological cyber IPV and cyberstalking with alcohol use were not significant in the present study, differing from previous findings that found psychological cyber IPV to be significantly associated with alcohol use.15,53 In the absence of prior research work examining the association between cyber IPV victimization types and alcohol use among LGB individuals we assume that the reasons for this findings may be attributable to the following. First, it maybe that the severity of cyber sexual IPV—duration, chronicity, number of perpetrators-was greater than the other two types of cyber IPV and in the context of the self-hypothesis, individuals would try and ease the emotion pain caused by severe sexual victimization by engaging in drinking behavior. Second, those with cyber sexual IPV are likely to be in non-supportive environment with enhanced risk of experiences minority stressors, such as heterosexism, which in turn is a risk factor of severity of alcohol drinking. 54 The current study did not examine these two aspects and future research studies should take into 
consideration severity of cyber IPV and the synergistic and detrimental effect of victimization and minority stressors on alcohol use in LGB emerging adults. Additionally, replication of the present findings is warranted as currently there is no study examining the effect of cyber IPV types on alcohol use after taking into account the effect of other types of interpersonal victimization. By utilizing the unique effect model, future research can help compartmentalize individual effects that different cyber IPV types have on psychological and behavioral outcomes. This informs clinical practice by highlighting cyber IPV types that are specifically affecting the use of alcohol in LGB emerging adults.

Although the unique effect model shows important correlations between the different cyber IPV types and alcohol use, the cumulative model uncovers the accumulating and detrimental effect that multiple types of abuse can have on an individual's wellbeing. The present findings partially align with the cumulative risk hypothesis in that those with exposure to three cyber IPV types reported increased alcohol use compared to those who experienced one type of cyber IPV; however, those endorsing 2-types of cyber IPV and non-victims had similar levels of alcohol use compared to 1-type of cyber IPV. Findings suggest that while a compounding effect of cyber IPV types on alcohol use exists, the pattern is not linear, that is, with an increase in cyber IPV types, a corresponding increase in alcohol use does not exist until the threshold of exposure to three types of cyber IPV is reached. To the best of our knowledge, the present study is the first to examine the additive effect of cyber IPV types on alcohol use and thus warrants replication. Nonetheless, these findings are in line with prior studies on interpersonal victimization that have documented an accumulating and negative effect of exposure to various types of interpersonal victimization types including, IPV among young adults. 18,24 
In addition to the hypotheses tested, there were other noteworthy findings. Nearly $80 \%$ LGB individuals reported having experienced one of the three face-to-face IPV types which is similar to the rates found in national samples on sexual minorities.3 Furthermore, the present study showed that being a person of color including Hispanic (Step 1), exposure to childhood physical abuse, physical neglect (Step 2), and being a victim of face-to-face sexual assault (Step 3) were significant predictors of alcohol use among LGB emerging adults. These findings were consistent with previous literature as racial-ethnic minorities, 43 people who have experienced childhood physical abuse and neglect,55-57 and survivors of sexual assault during adulthood 31 have shown to be risk factors of alcohol use. Further investigation is needed since there are mixed findings regarding the association between childhood physical neglect and alcohol use.17,58 Furthermore, although previous studies suggest bisexuals are especially vulnerable to alcohol use, the present study did not find a difference in alcohol use among different minority sexual orientations.41,42,59

The present study has the following limitations. First, the cross-sectional design's causal assumption of cyber IPV leading to alcohol use is assumed based on prior studies and the selfmedication hypothesis.37 Future studies should examine the association between cyber IPV and alcohol use in a longitudinal design. Second, the study sample was collected online and may not represent LGB people as a whole. Nonetheless, the anonymity provided to participants may increase comfort and willingness to disclose sensitive information about themselves.60-61 Third, the use of self-report questionnaires can cause recall bias; however, the measures used for childhood and adulthood victimization inquired behavior-specific questions that increases accuracy in reporting.62 Fourth, the present study did not examine the characteristics of cyber IPV (e.g., longer duration, higher frequency) associated with severe psychological problems.63 
Nonetheless, the findings have significant implications for clinical practice and future research studies. The unique effect of sexual cyber IPV, and the additive effect of the three cyber IPV types on alcohol use, indicates the importance of examining cyber IPV as a multidimensional form of interpersonal violence. While the harmful effect of stalking and psychological cyber IPV on alcohol use did not arise, they are still wrongful acts. Interventions focusing on disseminating awareness of cyber IPV and related negative psychological and behavioral consequences should be initiated among individuals with sexually diverse identities. Such efforts would encourage victims to disclose exposure to cyber IPV. Clinicians should assess interpersonal victimization, including cyber IPV types when working with LGB clients and couples at risk of partner violence, as should other practitioners (e.g., police, universities). Additionally, focusing on cyber IPV types will facilitate creating and defining laws and policies to protect victims.

In conclusion, by highlighting that cyber IPV is associated with alcohol use above and beyond the effect of childhood maltreatment and face-to-face IPV in LGB adults, the present findings challenge the common notion that technology-mediated interpersonal violence is not harmful as it lacks the physical nature of violence, absence of an in-person perpetrator, and the ability of an individual to step away from the technology-medium via which aggression occurs (e.g., switching off the phone). Future studies should engage in replicating the present findings and consider the role of risk and protective factors (e.g., autonomy, community connectedness) 63 that alleviate exposure to interpersonal victimization, including various types of cyber IPV in LGB emerging adults.64 


\section{References}

1. Grov C, Breslow AS, Newcomb ME, Rosenberger JG, Bauermeister JA. Gay and bisexual men's use of the internet: Research from the 1990s through 2013. Journal of Sex Research 2014; 51:390-409.

2. Rosenfeld MJ, Thomas RJ. Searching for a mate: The rise of the internet as a social intermediary. American Sociological Review 2012; 77:523-547.

3. Walters ML, Chen J, Brieding MJ. The National Intimate Partner and Sexual Violence Survey (NISVS): 2010 findings on victimization by sexual orientation. National Center for Injury Prevention and Control Division of Violence Prevention 2013.

4. Marganski A, Melander L. Intimate partner violence victimization in the cyber and real world: Examining the extent of cyber aggression experiences and its association with inperson dating violence. Journal of Interpersonal Violence 2018; 33:1071-1095.

5. Zapor H, Wolford-Clevenger C, Elmquist J, et al. Psychological aggression committed through technology: A study with dating college students. Partner Abuse 2017; 8:127-145.

6. Crane CA, Umehira N, Berbary C, Easton CJ. Problematic alcohol use as a risk factor for cyber aggression within romantic relationships. The American Journal on Addictions 2018; 27:400-406.

7. Operario D, Gamarel KE, Grin BM, Lee JH, et al. Sexual minority health disparities in adult men and women in the United States: National health and nutrition examination survey, 2001-2010. American Journal of Public Health 2015; 105:27-34.

8. Phillips G, Turner B, Salamanca P, et al. Victimization as a mediator of alcohol use disparities between sexual minority subgroups and sexual majority youth using the 2015 National Youth Risk Behavior Survey. Drug and Alcohol Dependence 2017; 178:355-362 
9. Wang K, White Hughto JM, Biello KB, et al. The role of distress intolerance in the relationship between childhood sexual abuse and problematic alcohol use among Latin American MSM. Drug and Alcohol Dependence 2017; 175:151-156.

10. Substance Abuse and Mental Health Services Administration. Results from the 2013 National Survey on Drug Use and Health: Summary of national findings. Substance Abuse and Mental Health Services Administration 2014; 32-33

11. Meyer IH. Minority stress and mental health in gay men. Journal of Health and Social Behavior 1995; 36:38-56.

12. Dank M, Lachman P, Zweig JM, Yahner J. Dating violence experiences of lesbian, gay, bisexual, and transgender youth. Journal of Youth and Adolescence 2014; 43:846-857.

13. Whitton SW, Dyar C, Mustanski B, Newcomb ME. Intimate partner violence experiences of sexual and gender minority adolescents and young adults assigned female at birth.

Psychology of Women Quarterly 2019; 43:232-249.

14. Charak R, Villarreal L, Schmitz RM, Hirai M, Ford JD. Patterns of childhood maltreatment and intimate partner violence, emotion dysregulation, and mental health symptoms among lesbian, gay, and bisexual emerging adults: A three-step latent class approach. Child Abuse \& Neglect 2019; 89:99-110.

15. Watkins LE, Maldonado RC, DiLillo D. The cyber aggression in relationships scale: A new multidimensional measure of technology-based intimate partner aggression. Assessment $2018 ; 25: 608-626$.

16. Adam EK, Chyu L, Hoyt LT, et al. Adverse adolescent relationship histories and young adult health: cumulative effects of loneliness, low parental support, relationship instability, intimate partner violence, and loss. Journal of Adolescent Health 2011; 49:278-286. 
17. Cohen JR, Menon SV, Shorey RC, Le VD, Temple, JR. The distal consequences of physical and emotional neglect in emerging adults: A person-centered, multi-wave, longitudinal study. Child Abuse \& Neglect 2017; 63:151-161.

18. Sabina C, Straus MA. (2008). Polyvictimization by dating partners and mental health among U.S. college students. Violence and Victims 2008; 23:667-682.

19. Thibodeau ME, Lavoie F, Hébert M, Blais M. Childhood maltreatment and adolescent sexual risk behaviors: Unique, cumulative and interactive effects. Child Abuse \& Neglect $2017 ; 72: 411-420$.

20. Drouin M, Ross J, Tobin E. Sexting: A new, digital vehicle for intimate partner aggression? Computers in Human Behavior 2015; 50:197-204.

21. Sargent KS, Krauss A, Jouriles EN, McDonald R. Cyber victimization, psychological intimate partner violence, and problematic mental health outcomes among first-year college students. Cyberpsychology, Behavior, and Social Networking 2016; 19:545-550.

22. Reed LA, Tolman RM, Ward LM. Gender matters: Experiences and consequences of digital dating abuse victimization in adolescent dating relationships. Journal of Adolescence 2017; 59:79-89.

23. Rutter M. Stress, coping and development: Some issues and some questions. Journal of Child Psychology and Psychiatry 1981; 22:323-356.

24. Lagdon S, Armour C, Stringer M. Adult experience of mental health outcomes as a result of intimate partner violence victimisation: A systematic review. European Journal of Psychotraumatology 2014, 5. 
25. McRae L, Daire AP, Abel EM, Lambie GW. A social learning perspective on childhood trauma and same-sex intimate partner violence. Journal of Counseling \& Development 2017; 95:332-338.

26. Gervais SJ, Davidson MM. Objectification among college women in the context of intimate partner violence. Violence and Victims 2013; 28:36-49.

27. Charak R, Koot HM, Dvorak RD, Elklit A, Elhai JD. Unique versus cumulative effects of physical and sexual assault on patterns of adolescent substance use. Psychiatry Research $2015 ; 230: 763-769$.

28. Gomez J, Becker S, O’Brien K, Spirito A. Interactive effect of child maltreatment and substance use on depressed mood among adolescents presenting to community-based substance use treatment. Community Mental Health Journal 2015; 51:833-840. doi:10.1007/s10597-015-9894-0

29. Grayson CE, Nolen-Hoeksema S. Motives to drink as mediators between childhood sexual assault and alcohol problems in adult women. Journal of Traumatic Stress 2005; 18:137145.

30. La Flair LN, Bradshaw CP, Storr CL, Green KM, Alvanzo AAH, Crum RM. Intimate partner violence and patterns of alcohol abuse and dependence criteria among women: A latent class analysis. Journal of Studies on Alcohol and Drugs 2012; 73:351-360.

31. Ullman SE, Sigurvinsdottir R. Intimate partner violence and drinking among victims of adult sexual assault. Journal of Aggression, Maltreatment \& Trauma 2015; 24:117-130.

32. Yalch MM, Levendosky AA. Main and moderating effects of temperament traits on the association between intimate partner violence and hazardous alcohol use in a sample of young adult women. Psychological Trauma 2018; 10:611-618. 
33. Edwards KM, Sylaska KM. The perpetration of intimate partner violence among LGBTQ college youth: The role of minority stress. Journal of Youth and Adolescence 2013; 42:1721-1731.

34. Edwards KM, Sylaska KM, Neal AM. Intimate partner violence among sexual minority populations: A critical review of the literature and agenda for future research. Psychology of Violence 2013; 5:112-121.

35. Boyle SC, LaBrie JW, Costine LD, Witkovic YD. "It's how we deal": Perceptions of LGB peers' use of alcohol and other drugs to cope and sexual minority adults' own coping motivated substance use following the Pulse nightclub shooting. Addictive Behaviors 2017; 65:51-55.

36. Kaysen D, Dillworth TM, Simpson T, Waldrop A, Larimer ME, Resick PA. Domestic violence and alcohol use: Trauma-related symptoms and motives for drinking. Addictive Behaviors 2007; 32:1272-1283.

37. Khantzian EJ. The self-medication hypothesis of substance use disorders: A reconsideration and recent applications. Harvard Review of Psychiatry. 2014; 4:231-244.

38. de Lint W, Marmo M, Groves A, Pocrnic A. Crime victims' self-medication: Findings from a study in South Australia. International Review of Victimology 2017; 23:159-177.

39. Swendsen JD, Tennen H, Carney MA, Affleck G, Willard A, Hromi A. Mood and alcohol consumption: an experience sampling test of the self-medication hypothesis. Journal of Abnormal Psychology 2000; 109:198-204.

40. Hughes TL, Johnson TP, Wilsnack SC, Szalacha LA. Childhood risk factors for alcohol abuse and psychological distress among adult lesbians. Child Abuse \& Neglect 2007; 31:769-789. 
41. Lewis RJ, Mason TB, Winstead BA, Gaskins M, Irons LB. Pathways to hazardous drinking among racially and socioeconomically diverse lesbian women: Sexual minority stress, rumination, social isolation, and drinking to cope. Psychology of Women Quarterly 2016; 40:564-581.

42. Ahrnsbrak R, Bose J, Hedden SL, Lipari RN, Park-Lee E, Tice P. National survey on drug use and health key substance use and mental health indicators in the United States: Results from the 2016 national survey on drug use and health. Center for Behavioral Health Statistics and Quality, substance Abuse and Mental Health Service Administration 2016;1113

43. Chartier K, Caetano R. Ethnicity and health disparities in alcohol research. Alcohol Research \& Health 2010; 33:152-160.

44. Chan SF, La Greca AM. Cyber victimization and aggression: Are they linked with adolescent smoking and drinking? Child \& Youth Care Forum 2016; 45:47-63.

45. Buhrmester M, Kwang T, Gosling SD. Amazon's Mechanical Turk: A new source of inexpensive, yet high-quality, data? Perspectives of Psychological Science 2011; 6:3-5.

46. Bernstein DP, Stein JA, Newcomb MD, et al. Development and validation of a brief screening version of the Childhood Trauma Questionnaire. Child Abuse \& Neglect 2003; 27:169-190.

47. Straus MA, Douglas EM. A short form of the revised conflict tactics scales, and typologies for severity and mutuality. Violence and Victims 2004; 19: 507-520.

48. Balsam KF, Rothblum ED, Beauchaine TP. Victimization Over the Life Span: A Comparison of Lesbian, Gay, Bisexual, and Heterosexual Siblings. Journal of Consulting and Clinical Psychology 2005; 73:477-487. 
49. Saunders JB, Aasland OG, Babor TF, De La Fuente JR, Grant M. Development of the Alcohol Use Disorders Identification Test (AUDIT): WHO collaborative project on early detection of persons with harmful alcohol consumption-II. Addiction 1993; 88:791-804.

50. Reinert DF, Allen JP. The Alcohol Use Disorders Identification Test (AUDIT): A review of recent research. Alcoholism: Clinical and Experimental Research 2002; 26:272-279.

51. Hughes, TL, Szalacha LA, Johnson TP, Kinnison KE, Wilsnack SC, Cho Y. Sexual victimization and hazardous drinking among heterosexual and sexual minority women. Addictive Behaviors 2010; 35:1152-1156.

52. Rhew IC, Stappenbeck CA, Bernard-Gilligan M, Hughes T, Kaysen D. Effects fo sexual assault on alcohol use and consequences among young adult sexual minority women. Journal of Consulting and Clinical Psychology 2017; 85:424-433.

53. Van Ouytsel J, Ponnet K, Walrave M, Temple JR. Adolescent cyber dating abuse victimization and its associations with substance use, and sexual behaviors. Public Health. 2016; 135:147-151.

54. Wilson SM, Gilmore AK, Rhew IC, Hodge KA, Kaysen DL. Minority stress is longitudinally associated with alcohol-related problems among sexual minority women. Addictive Behaviors 2016; 61:80-83.

55. Herrenkohl TI, Hong S, Klika JB, Herrenkohl RC, Russo MJ. Developmental impacts of child abuse \& neglect related to adult mental health, substance use, and physical health. Journal of Family Violence 2012; 28:191-199.

56. Kilpatrick DG, Acierno R, Saunders B, Resnick HS, Best CL, Schnurr PP. Risk factors for adolescent substance abuse and dependence: Data from a national sample. Journal of Consulting and Clinical Psychology 2000; 68:19-30. 
57. Skinner ML, Hong S, Herrenkohl TI, Brown EC, Lee JO, Jung H. Longitudinal effects of early childhood maltreatment on co-occurring substance misuse and mental health problems in adulthood: The role of adolescent alcohol use and depression. Journal of Studies on Alcohol and Drugs 2016; 77:464-472.

58. Norman RE, Byambaa M, De R, Butchart A, Scott J, Vos T. The long-term health consequences of child physical abuse, emotional abuse, and neglect: A systematic review and meta-analysis. Public Library of Science Medicine 2012; 9:1-31.

59. Newcomb ME, Heinz AJ, Mustanski B. Examining risk and protective factors for alcohol use in lesbian, gay, bisexual, and transgender youth: A longitudinal multilevel analysis. Journal of Studies on Alcohol and Drugs. 2012; 73:783-793.

60. Shapiro DN, Chandler J, Mueller PA. Using Mechanical Turk to study clinical populations. Clinical Psychological Science 2013; 1:213-220.

61. Thomas KA, Clifford S. Validity and Mechanical Turk: An assessment of exclusion methods and interactive experiments. Computers in Human Behavior 2017; 77:184-197.

62. Fricker AE, Smith DW, Davis JL, Hanson RF. Effects of context and question type on endorsement of childhood sexual abuse. Journal of Traumatic Stress 2003, 16:265-268.

63. Schmitz RM, Sanchez J, Lopez B. LGBTQ+ Latinx young adults health autonomy in resisting cultural stigma. Culture, Health and Sexuality 2019, 21:16-30.

64. Charak R, DiLillo D, Messman-Moore TL, Gratz KL. Latent classes of lifetime sexual victimization characteristics in women in emerging adulthood: Differential relations with emotion dysregulation. Psychology of Violence 2018; 8:570-579. 
Table 1

Distribution of Race-ethnic Minority Status and CAN and IPV types in LGB Emerging Adults

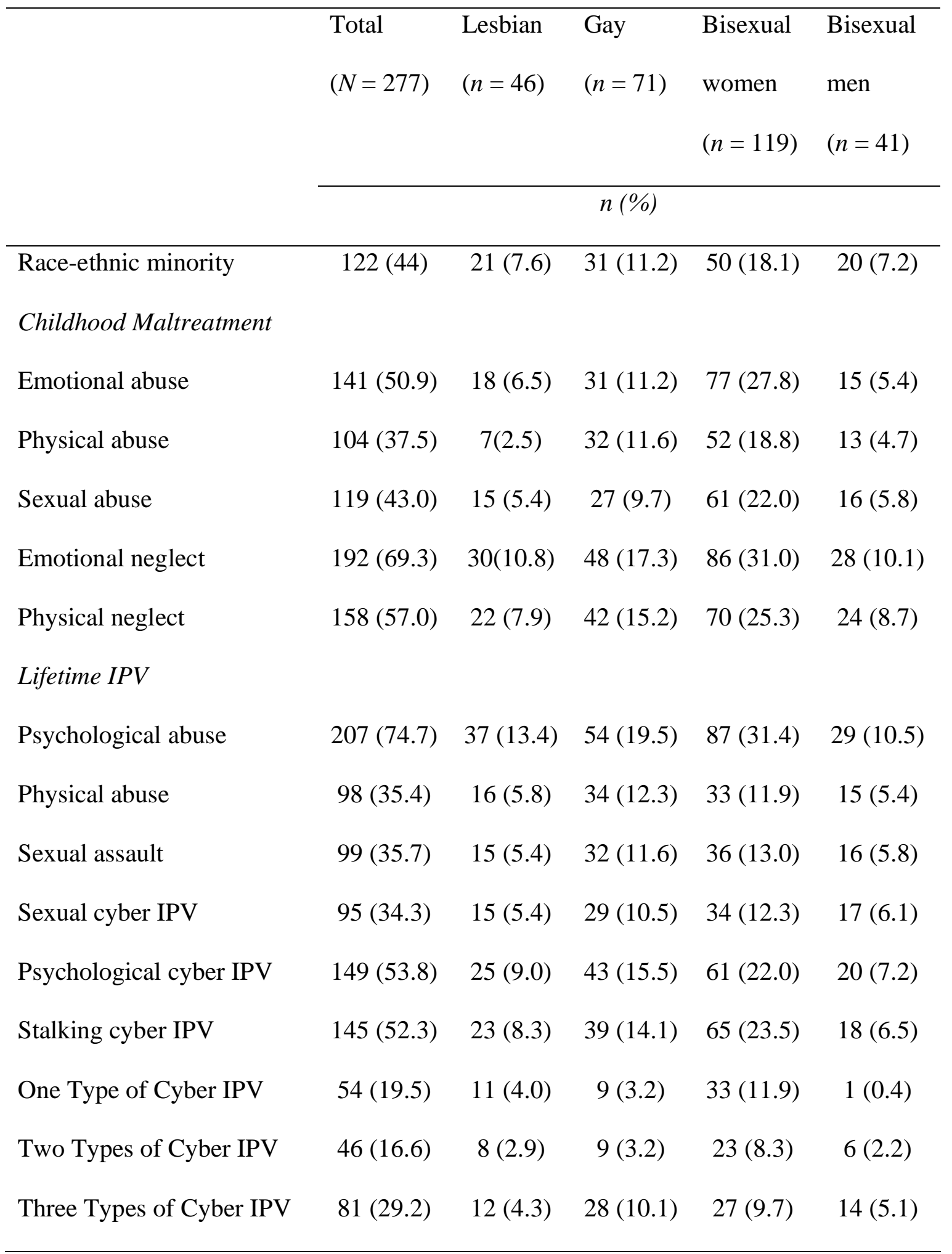


Note. IPV = Intimate partner violence victimization. Race-ethnic minority includes people of color and white Hispanic individual. 
CYBERVICTIMIZATION AND ALCOHOL USE

Table 2

Correlations for study variables

\begin{tabular}{|c|c|c|c|c|c|c|c|c|c|c|c|c|c|c|c|c|c|c|c|c|}
\hline Variable & 1 & 2 & 3 & 4 & 5 & 6 & 7 & 8 & 9 & 10 & 11 & 12 & 13 & 14 & 15 & 16 & 17 & 18 & 19 & 20 \\
\hline 1.Alcohol & -- & & & & & & & & & & & & & & & & & & & \\
\hline 2.Age & -.04 & -- & & & & & & & & & & & & & & & & & & \\
\hline 3.POC & .15 & .03 & -- & & & & & & & & & & & & & & & & & \\
\hline 4.Gay & .09 & -.04 & -.00 & -- & & & & & & & & & & & & & & & & \\
\hline 5.Lesbian & -.05 & -.00 & .01 & -.26 & -- & & & & & & & & & & & & & & & \\
\hline 6.Bisexual & -.04 & -.03 & .04 & -.25 & -.19 & -- & & & & & & & & & & & & & & \\
\hline 7.CEA & .22 & .05 & -.00 & -.12 & -.12 & -.11 & -- & & & & & & & & & & & & & \\
\hline 8.CPA & .41 & .09 & .19 & .12 & -.17 & -.01 & .60 & -- & & & & & & & & & & & & \\
\hline 9.CSA & .32 & .16 & .19 & -.02 & -.10 & -.06 & .56 & .60 & -- & & & & & & & & & & & \\
\hline 10.CEN & .06 & -.03 & .06 & -.04 & -.06 & -.01 & .45 & .25 & .25 & -- & & & & & & & & & & \\
\hline 11.CPN & .30 & .03 & .13 & .07 & -.09 & .03 & .44 & .53 & .45 & .61 & -- & & & & & & & & & \\
\hline \multicolumn{21}{|c|}{ Face-to-face IPV } \\
\hline 12.PSY & .17 & -.04 & .10 & .02 & .06 & -.04 & .06 & .12 & .09 & -.07 & .02 & -- & & & & & & & & \\
\hline 13.PHY & .21 & -.08 & .12 & .15 & -.01 & .01 & .16 & .40 & .23 & .21 & .36 & .36 & -- & & & & & & & \\
\hline 14.SEX & .24 & -.05 & .08 & .11 & -.03 & .03 & .05 & .27 & .19 & .19 & .33 & .31 & .72 & -- & & & & & & \\
\hline
\end{tabular}


Cyber IPV

\begin{tabular}{|c|c|c|c|c|c|c|c|c|c|c|c|c|c|c|c|c|}
\hline 15.SEX & .36 & -.05 & .09 & .08 & -.02 & .06 & .14 & .32 & .27 & .12 & .33 & .21 & .34 & .35 & -- & \\
\hline 16.PSY & .27 & -.04 & .09 & .08 & .01 & -.04 & .19 & .27 & .13 & .08 & .18 & .26 & .29 & .22 & .52 & -- \\
\hline 17.STLK & .31 & .01 & .10 & .03 & -.02 & -.07 & .20 & .35 & .25 & .12 & .30 & .23 & .31 & .30 & .54 & .59 \\
\hline
\end{tabular}

Cumulative cyber IPV

\begin{tabular}{|c|c|c|c|c|c|c|c|c|c|c|c|c|c|c|c|c|c|c|c|c|}
\hline 18.0-types & -.26 & -.01 & -.07 & .01 & -.02 & .12 & -.20 & -.27 & -.19 & -.03 & -.15 & -.29 & -.22 & -.21 & -- & -- & -- & -- & & \\
\hline$M$ & 2.84 & 25.39 & -- & -- & -- & -- & 10.41 & 7.94 & 8.47 & 13.39 & 9.47 & .75 & 0.35 & .36 & .34 & .52 & .54 & .35 & .17 & .29 \\
\hline$S D$ & 3.96 & 2.77 & -- & -- & -- & -- & 5.58 & 4.08 & 5.16 & 5.71 & 4.16 & .44 & .48 & .48 & .48 & .50 & .50 & .48 & .37 & .46 \\
\hline
\end{tabular}

Note . $\mathrm{POC}=$ People of color, $\mathrm{CEA}=$ Childhood emotional abuse, $\mathrm{CPA}=$ Childhood physical abuse, $\mathrm{CSA}=\mathrm{Childhood}$ sexual abuse $\mathrm{CEN}=$ Childhood emotional neglect, $\mathrm{CPN}=$ Childhood physical neglect, IPV $=$ Intimate partner violence victimization. $\mathrm{CIPV}=$ Cyber intimate partner Victimization. PSY = Psychological victimization. SEX = Sexual victimization. PHY $=$ Physical victimization. STLK = Stalking.

Italicized $=p<.05$, Underlined $=p<.01$, Boldface $=p<.001$ 
Table 3

Hierarchical Regression Predicting the Unique Effect of Three Types of Cyber IPV on Alcohol Use After Controlling for Covariates

\begin{tabular}{|c|c|c|c|c|c|c|c|c|}
\hline \multirow[b]{2}{*}{ Variable } & \multicolumn{2}{|c|}{ Step 1} & \multicolumn{2}{|c|}{ Step 2} & \multicolumn{2}{|c|}{ Step 3} & \multicolumn{2}{|c|}{ Step 4} \\
\hline & $\beta$ & $t$ & $\beta$ & $t$ & $\beta$ & $t$ & $\beta$ & $t$ \\
\hline Age & -.04 & -.65 & -.09 & -1.63 & -.09 & -1.54 & -.07 & -1.36 \\
\hline Race-ethnic minority & .15 & $2.48 *$ & .06 & 1.00 & .05 & .94 & .05 & .71 \\
\hline Gay men & .07 & 1.10 & .03 & .47 & .03 & .54 & .03 & .43 \\
\hline Lesbian women & -.04 & -.59 & .02 & .31 & .02 & .31 & .01 & .16 \\
\hline Bisexual men & -.04 & -.57 & -.03 & -.57 & -.03 & -.51 & -.04 & -.62 \\
\hline Emotional abuse & & & -.04 & -.42 & -.02 & -.20 & -.01 & -.14 \\
\hline Physical abuse & & & .30 & $3.64 *$ & .30 & $3.54 *$ & .27 & $3.11 *$ \\
\hline Sexual abuse & & & .11 & 1.50 & .10 & 1.32 & .08 & 1.13 \\
\hline Emotional neglect & & & -.14 & -1.92 & -.13 & -1.77 & -.12 & -1.60 \\
\hline Physical neglect & & & .18 & $2.28 *$ & .17 & $2.06 *$ & .13 & 1.55 \\
\hline Psychological abuse & & & & & .10 & 1.63 & .07 & 1.09 \\
\hline Physical abuse & & & & & -.13 & -1.51 & -.14 & -1.49 \\
\hline Sexual assault & & & & & .16 & $2.00 *$ & .13 & 1.58 \\
\hline Sexual cyber IPV & & & & & & & .15 & $2.16 *$ \\
\hline Psychological cyber IPV & & & & & & & .05 & .76 \\
\hline Stalking cyber IPV & & & & & & & .05 & .64 \\
\hline$R^{2}$ & .03 & & .21 & & .24 & & .27 & \\
\hline$F$ & 1.83 & & $7.20 *$ & & $6.22 *$ & & $6.01 *$ & \\
\hline$\Delta R^{2}$ & .03 & & .18 & & .02 & & .04 & \\
\hline
\end{tabular}


CYBERVICTIMIZATION AND ALCOHOL USE
$\Delta F$
1.83
$12.19^{*}$
2.54
$4.14^{*}$

Note. F2F = Face-to-face. IPV = Intimate partner violence victimization .

$* p<.05$ 
Table 4

Hierarchical Regression Examining the Cumulative Effect of Three Types of Cyber IPV on Alcohol use After Controlling for Covariates

\begin{tabular}{|c|c|c|c|c|c|c|c|c|}
\hline \multirow[b]{2}{*}{ Variable } & \multicolumn{2}{|c|}{ Step 1} & \multicolumn{2}{|c|}{ Step 2} & \multicolumn{2}{|c|}{ Step 3} & \multicolumn{2}{|c|}{ Step 4} \\
\hline & $\beta$ & $t$ & $\beta$ & $t$ & $\beta$ & $t$ & $\beta$ & $t$ \\
\hline Age & -.04 & -.65 & -.09 & -1.63 & -.09 & -1.54 & -.07 & -1.23 \\
\hline Race-ethnic minority & .15 & $2.48 *$ & .06 & 1.00 & .05 & .94 & .06 & .99 \\
\hline Gay men & .07 & 1.10 & .03 & .47 & .03 & .54 & .02 & .29 \\
\hline Lesbian women & -.04 & -.59 & .02 & .31 & .02 & .31 & .01 & .12 \\
\hline Bisexual men & -.04 & -.57 & -.03 & -.57 & -.03 & -.51 & -.04 & -.45 \\
\hline Emotional abuse & & & -.04 & -.42 & -.02 & -.20 & -.01 & -.06 \\
\hline Physical abuse & & & .30 & $3.64 *$ & .30 & $3.54 *$ & .27 & $3.13^{*}$ \\
\hline Sexual abuse & & & .11 & 1.50 & .10 & 1.32 & .07 & .75 \\
\hline Emotional neglect & & & -.14 & -1.92 & -.13 & -1.77 & -.13 & -1.70 \\
\hline Physical neglect & & & .18 & $2.28 *$ & .17 & $2.06^{*}$ & .11 & 1.41 \\
\hline Psychological abuse & & & & & .10 & 1.63 & .07 & 1.20 \\
\hline Physical abuse & & & & & -.13 & -1.51 & -.15 & -1.72 \\
\hline Sexual assault & & & & & .16 & $2.00 *$ & .12 & 1.47 \\
\hline No cyber IPV & & & & & & & -.05 & -.63 \\
\hline Two types of cyber IPV & & & & & & & -.01 & -.12 \\
\hline Three types of cyber IPV & & & & & & & .22 & $2.71 *$ \\
\hline$R^{2}$ & .03 & & .21 & & .24 & & .28 & \\
\hline$F$ & 1.83 & & $7.20 *$ & & $6.22 *$ & & $6.23 *$ & \\
\hline$\Delta R^{2}$ & .03 & & .18 & & .02 & & .04 & \\
\hline
\end{tabular}


CYBERVICTIMIZATION AND ALCOHOL USE
$\Delta F$
1.83
$12.19^{*}$
2.54
$5.02 *$

Note. $\mathrm{F} 2 \mathrm{~F}=$ Face-to-face. IPV = Intimate partner violence victimization .

${ }^{*} p<.05$ 